\title{
Structurally Stable and Highly Enhanced \\ Luminescent Perovskite Based on Quasi-Two- \\ Dimensional Structures upon addition of \\ Guanidinium Cations
}

\section{Supporting Information}

Wonhee Cha, ${ }^{+}$Hyowon Han, ${ }^{\ddagger}$ Yongseok Hong, ${ }^{\dagger}$ Gakhyun Kim,${ }^{\dagger}$ Cheolmin Park, ${ }^{\ddagger}$ and

\author{
Dongho Kim ${ }^{*+}$
}

† Spectroscopy Laboratory for Functional m-Electronic Systems and Department of

Chemistry, Yonsei University, 50 Yonsei-ro, Seodaemun-gu, Seoul 03722, Republic of Korea 
‡Department of Materials Science and Engineering, Yonsei University, 50 Yonsei-ro,

Seodaemun-gu, Seoul 03722, Republic of Korea 


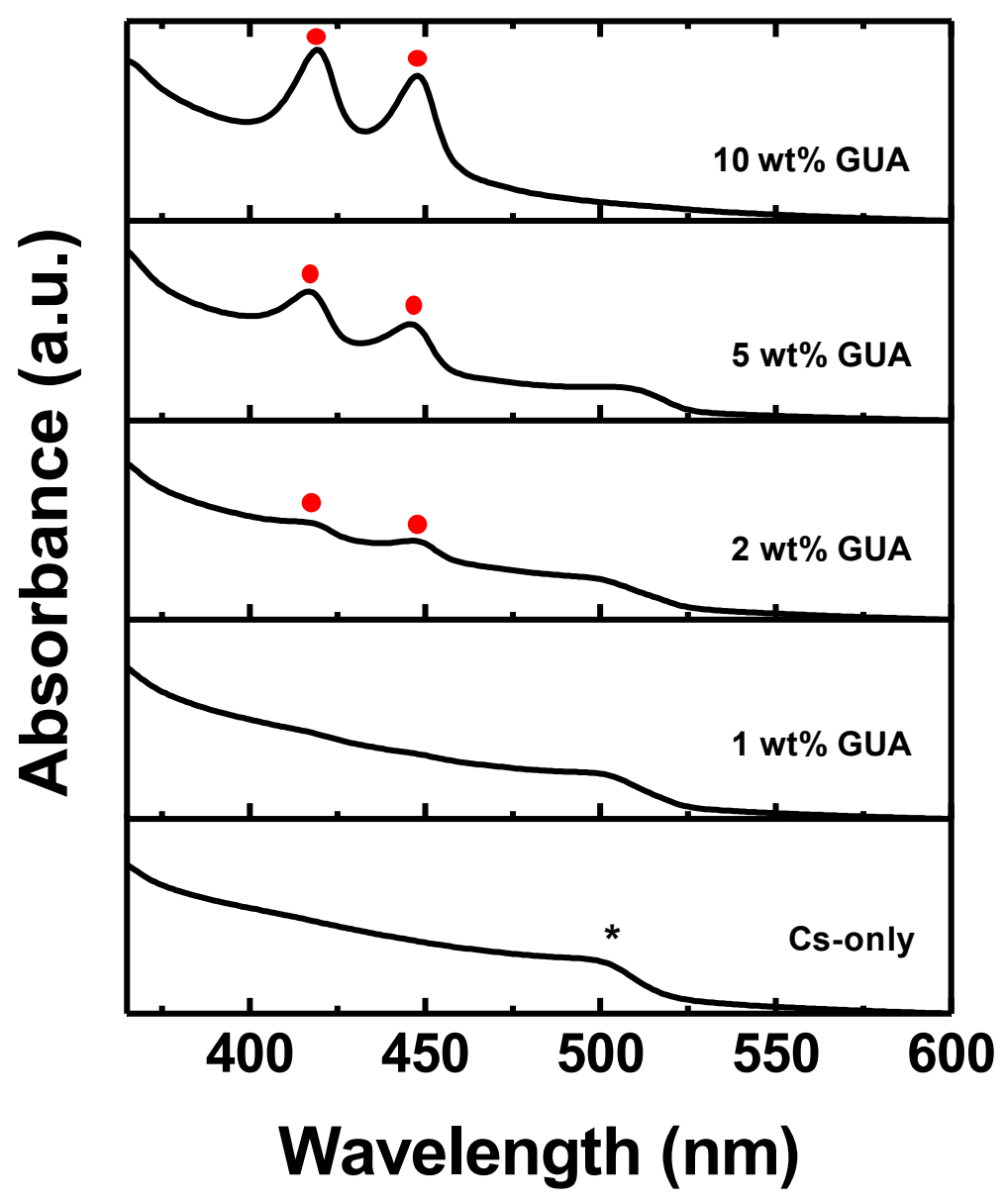

Figure S1. UV-Vis absorption spectra of $\mathrm{CsPbBr} 3$ perovskite films prepared with different amount of addition of GUA A-site cations. Asterisk $\left(^{*}\right)$ represents the absorption of the $3 \mathrm{D}$ structure of $\mathrm{CsPbBr}_{3}$, and the red dots represent the absorption of $2 \mathrm{D}$ and quasi-2D structures. 

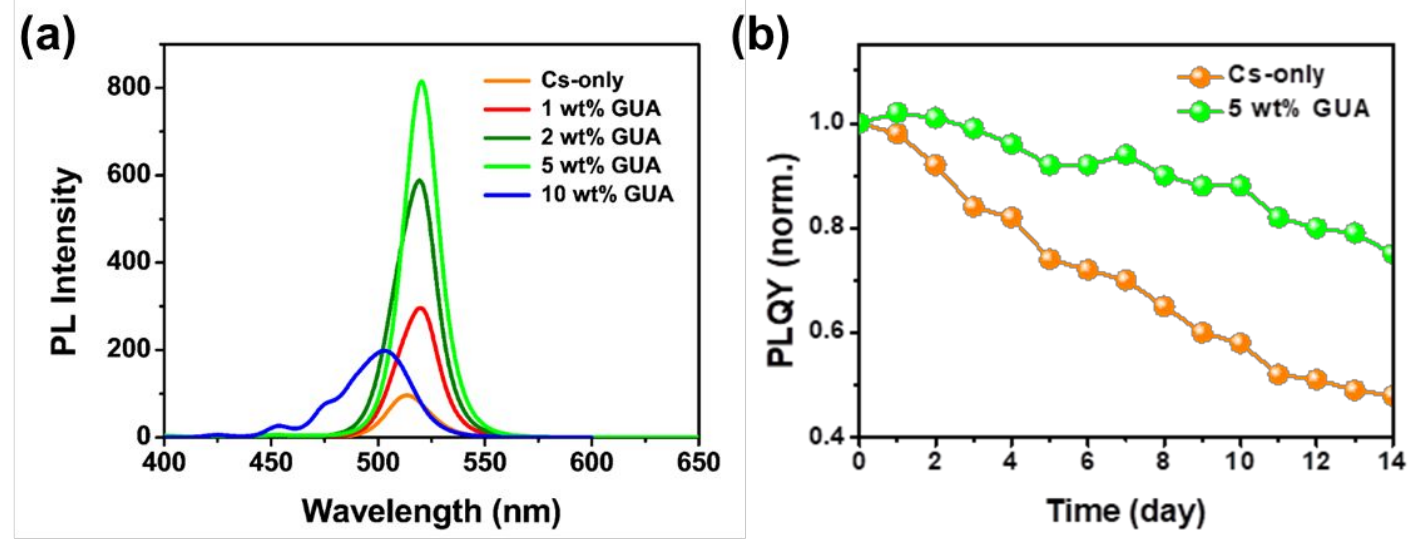

Figure S2. (a) Photoluminescence (PL) spectra of perovskite films with different amount of addition of GUA A-site cations. The $5 \mathrm{wt} \%$ GUA perovskite film shows high PL intensity compared with the other films. The all PL measurements of perovskite films were performed with the same excitation wavelength $\left(\lambda_{\mathrm{ex}}=365 \mathrm{~nm}\right)$ and emission slit width. (b) Degradation of PLQYs for Cs-only and 5 wt\% GUA perovskite films under ambient conditions with a relative humidity $\sim 60 \%$. 
(a)

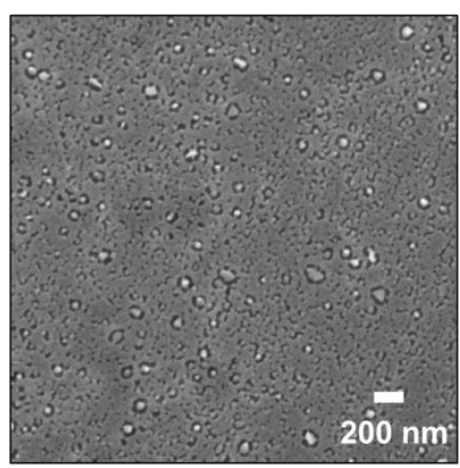

(c)

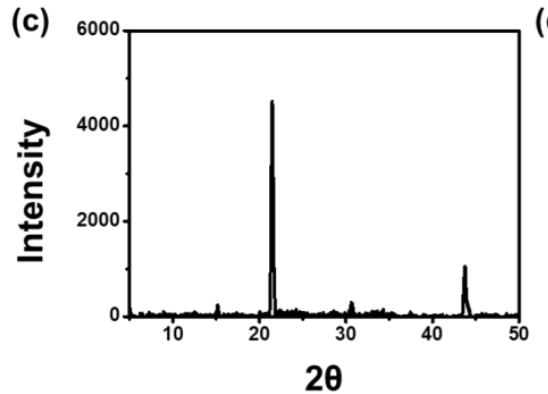

(b)

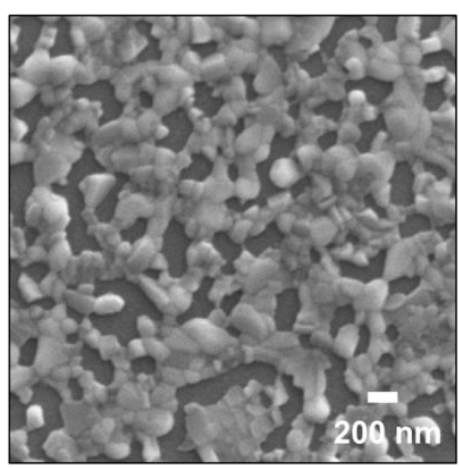

(d)

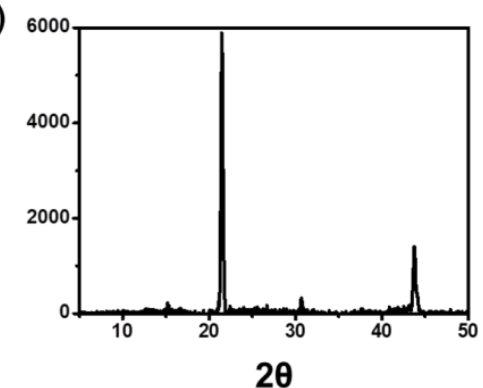

Figure S3. SEM images of (a) $1 \mathrm{wt} \%$, and (b) $2 \mathrm{wt} \%$ GUA perovskite film. HR-XRD pattern of (c) $1 \mathrm{wt} \%$, and (d) $2 \mathrm{wt} \%$ GUA perovskite film.

(a)

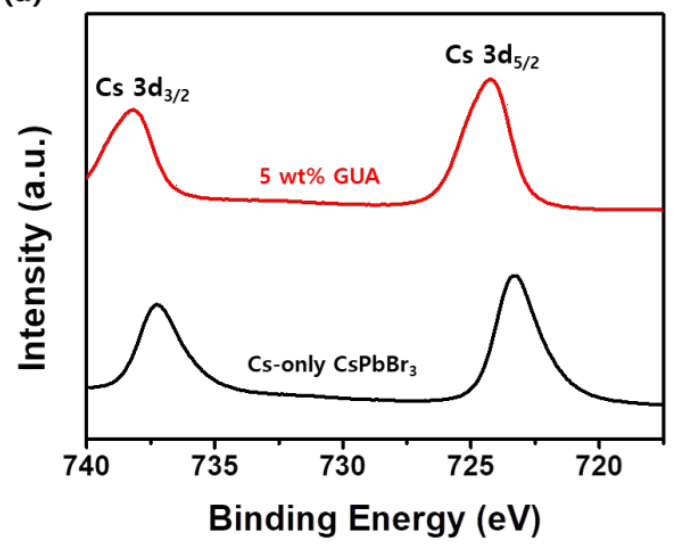

(b)

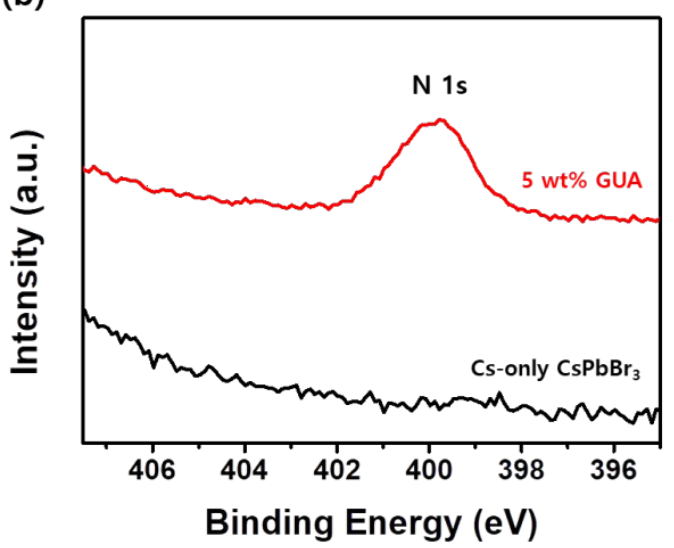

Figure S4. XPS spectra of perovskite films with and without GUA A-site cations. (a)

Cs $3 d$ and (b) N 1s. 

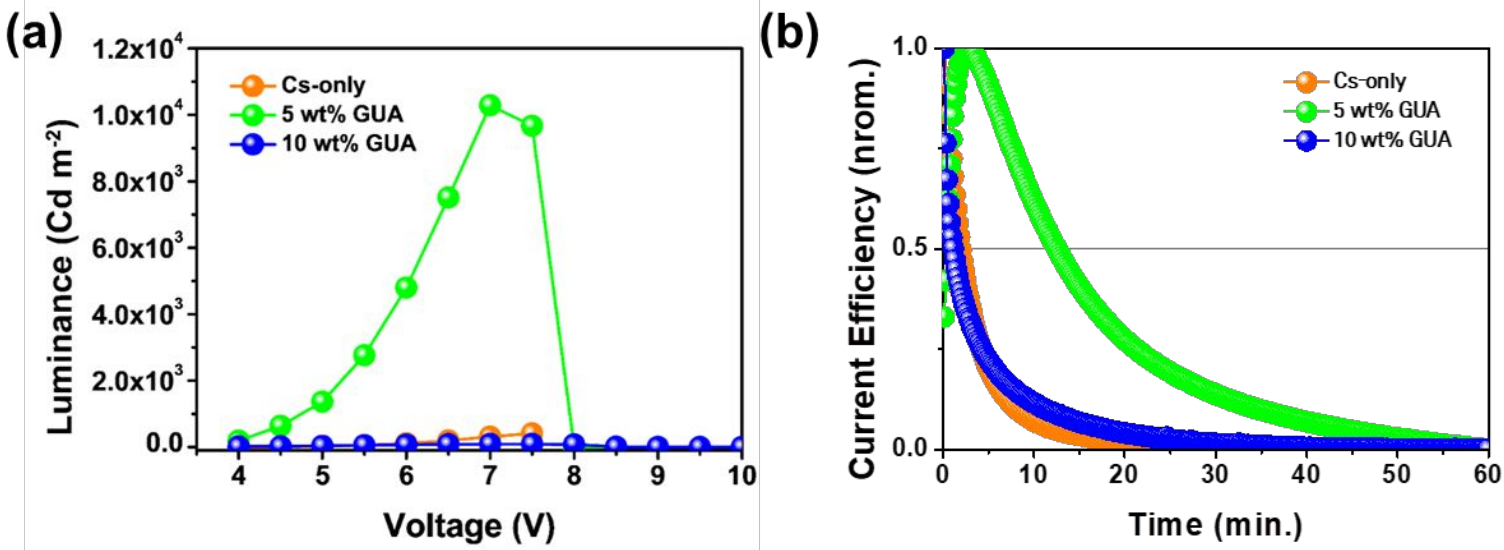

Figure S5. (a) Luminance-Voltage ( $L-V$ ) curves of perovskite LEDs fabricated with different amount of addition of GUA cation. (b) Operational lifetime of perovskite LEDs under constant applied voltage of $5.0 \mathrm{~V}$.

Table S1. Summary of device efficiencies of perovskite light-emitting diodes with different amount of addition of GUA A-site cations.

\begin{tabular}{|c|c|c|c|c|c|}
\hline \multirow{2}{*}{$\begin{array}{c}\text { GUA carion } \\
\text { (wt } \%)\end{array}$} & \multirow{2}{*}{$\begin{array}{l}\text { Lmax } \\
\left(\mathrm{Cd} \mathrm{m}^{-2}\right)\end{array}$} & \multirow{2}{*}{$\begin{array}{c}\text { Current } \\
\text { Efficiency } \\
\left(\mathrm{Cd} \mathrm{A}^{-1}\right)\end{array}$} & \multirow{2}{*}{$\begin{array}{l}\text { EQE } \\
(\%)\end{array}$} & \multicolumn{2}{|c|}{$\lambda_{\text {emission peak }}(\mathrm{nm})$} \\
\hline & & & & PL & $\mathrm{EL}$ \\
\hline 0 & 410 & 0.23 & 0.07 & 513 & 514 \\
\hline 1 & 2,100 & 0.64 & 0.20 & 519 & 513 \\
\hline
\end{tabular}




\begin{tabular}{|l|c|c|c|c|c|}
\hline 2 & 5,200 & 3.32 & 1.89 & 518 & 517 \\
\hline 5 & 10,200 & 9.43 & 2.62 & 520 & 518 \\
\hline & & & & 426 & 452 \\
10 & 90 & 0.91 & 0.37 & 453 & 473 \\
& & & & 475 & 502 \\
& & & & 502 & \\
\hline
\end{tabular}

